\title{
ORIENTASI STRATEGI YANG MEMPENGARUHI KINERJA ORGANISASI USAHA KECIL MENENGAH DI JAKARTA
}

\author{
Kadek Arya Jaya Kusuma \\ Program Studi Magister Manajemen Universitas Tarumanagara \\ kadek.117191034@stu.untar.ac.id \\ Eddy Supriyatna Marizar \\ Program Studi Magister Manajemen Universitas Tarumanagara
}

Masuk : 01-12-2020, revisi : 22-12-2020, diterima untuk diterbitkan : 23-12-2020

\begin{abstract}
The purpose of this study was to examine the effect of market orientation, technology orientation, and entrepreneurial orientation on the performance of small and medium enterprises in Jakarta. The sample was selected using the non-probability sampling method, amounting to 100 respondents who are entrepreneurs or entrepreneurs in the field of small and medium scale enterprises. Data processing techniques using the SmartPLS 3.0 program. The results of this study indicate that there is a significant influence between market orientation on organizational performance, there is a significant influence between technology orientation on organizational performance, and there is a significant influence between entrepreneurial orientation on organizational performance.
\end{abstract}

Keywords: Market Orientation, Technology Orientation, Entrepreneurial Orientation, Organizational Performance

Abstrak: Tujuan penelitian ini adalah untuk menguji pengaruh orientasi pasar, orientasi teknologi dan orientasi kewirausahaan terhadap kinerja organisasi usaha kecil dan menengah di Jakarta. Sampel dipilih menggunakan metode non-probability sampling berjumlah 100 responden yang merupakan pelaku usaha atau wirausaha dalam bidang skala usaha kecil dan menengah. Teknik pengolahan data menggunakan program SmartPLS 3.0. Hasil penelitian ini menunjukan bahwa adanya pengaruh signifikan antara orientasi pasar terhadap kinerja organisasi, adanya pengaruh yang signifikan antara orientasi teknologi terhadap kinerja organisasi, dan adanya pengaruh yang signifikan antara orientasi kewirausahaan terhadap kinerja organisasi.

Kata Kunci: Orientasi Pasar, Orientasi Teknologi, Orientasi Kewirausahaan, Kinerja Organisasi

\section{PENDAHULUAN}

Berdasarkan data yang dikeluarkan oleh Badan Pusat Statistik (BPS) (2018), Indonesia setiap tahunnya diprediksi mengalami pertumbuhan jumlah penduduk. Pada tahun 2010, jumlah penduduk Indonesia berkisar 238 juta jiwa dan diproyeksikan akan terus meningkat hingga 305 juta jiwa pada tahun 2035. Bambang Brodjonegoro yang merupakan Menteri Perencanaan Pembangunan Nasional (PPN) mengatakan Indeks Modal Manusia di Indonesia berada pada peringkat ke 87 dari 157 negara atau hanya sebesar 0,53. Pernyataan tersebut menyusul laporan yang dikeluarkan oleh World Bank terkait Human Capital Index.

Rendahnya indeks modal manusia dan tingginya pertumbuhan penduduk Indonesia pada setiap tahun akan membuat tingkat persaingan dalam perekonomian. Ketua umum Himpunan Pengusaha Muda Indonesia (HIMPI), Mardani mengatakan seiringnya pertumbuhan pelaku usaha di Indonesia setiap tahunnya juga di imbangi dengan ketidak mampuan wirausaha dalam mempertahankan usahanya menghadapi beratnya persaingan (Maming, 2019). 
Usaha Kecil dan Menengah (UKM) telah dianggap sebagai salah satu faktor penting dibalik keberhasilan ekonomi negara-negara maju dan berkembang karena kontribusinya dalam pertumbuhan ekonomi seperti penciptaan lapangan kerja dan inovasi (Kongolo, 2010). Martowardojo salah satu petinggi Bank Indonesia (BI) dalam Kompas (2017) juga menyatakan bahwa UKM memiliki peran penting untuk perekonomian Indonesia, hal ini dikarenakan UKM mampu melakukan penyerapan tenaga kerja dan peningkatankan penjualan ekspor yang berdampak terhadap pertumbuhan ekonomi.

Untuk meningkatkan kinerja organisasi UKM, orientasi pasar dikatakan mampu menciptakan budaya dan perilaku organisasi yang berfokus pada pengumpulan informasi mengenai kebutuhan pelanggan, kemampuan pesaing, dan lingkungan pasar yang dapat menjadi faktor penting dalam mencapai kinerja yang unggul (Kohli \& Jaworski, 1990; Slater \& Narver, 1994). Selain orientasi pasar, orientasi teknologi disebut sebagai salah satu dimana organisasi memiliki fokus $R \& D$ dan menekankan untuk memperoleh serta menggabungkan teknologi baru dalam pengembangan produk (Deshpandé et al., 2013, p. 232). Disamping orientasi pasar dan orientasi teknologi, orientasi kewirausahaan dikatakan mencerminkan visi manajerial dalam praktik pengambilan keputusan strategis, perilaku yang bersifat kewirausahaan, dan filosofi manajemen yang memungkinkan berkelanjutan keunggulan kompetitif dari waktu ke waktu dan pertumbuhan serta pembaruan perusahaan (Wales et al., 2013).

\section{Tujuan Penelitian}

Penelitian ini bertujuan untuk mengetahui pengaruh dari masing-masing variabel independen Orientasi Pasar, Orientasi Teknologi dan Orientasi Kewirausahaan terhadap variabel dependen Kinerja Organisasi pada Usaha Kecil dan Menengah (UKM) di Jakarta atau apabila dijabarkan penelitian ini bertujuan untuk mengetahui:

1. Untuk mengetahui pengaruh Orientasi Pasar terhadap Kinerja Organisasi pada Usaha Kecil dan Menengah di Jakarta.

2. Untuk mengetahui pengaruh Orientasi Teknologi terhadap Kinerja Organisasi pada Usaha Kecil dan Menengah di Jakarta.

3. Untuk mengetahui pengaruh Orientasi Kewirausahaan terhadap Kinerja Organisasi pada Usaha Kecil dan Menengah di Jakarta.

\section{TINJAUAN PUSTAKA \\ Orientasi Pasar}

Kara et al. (2005) mengatakan orientasi pasar merupakan budaya organisasi yang menjadikan konsumen sebagai yang paling utama dalam merencakan bisnis. Narver dan Slater (1990) mengatakan dalam orientasi pasar terdapat tiga komponen perilaku, yaitu orientasi pelanggan, pesaing dan koordinasi interfungsional. Sebagai inti dari komponen perilaku dalam orientasi pasar, orientasi pelanggan diartikan sebagai pemahaman yang memadai tentang target beli pelanggan dengan menempatkan kebutuhan dan kepetingan pelanggan pada urutan pertama. Selanjutnya, orientasi pesaing memberikan pandangan terhadap perusahaan dalam memahami kekuatan dan kelemahan strategi serta kapabilitas jangka pendek maupun jangka panjang yang dimiliki oleh pesaing. Sedangkan, koordinasi interfungsional mendasarkan perusahaan dalam menciptakan nilai unggul untuk konsumen yang ditargetkan dengan mengkordinasikan pendayagunaan semua sumber daya perusahaan.

\section{Orientasi Teknologi}

Gatignon dan Xuereb (1997) mengatakan orientasi teknologi merupakan kemampuan yang diimbangi dengan kemauan untuk memperoleh latar belakang teknologi dan menggunakannya dalam pengembangan produk baru. Orientasi teknologi juga diartikan dengan pengetahuan teknologi yang dapat digunakan oleh perusahaan dalam membangun solusi teknis untuk memenuhi kebutuhan pengguna. Teknologi orientasi merupakan faktor penting yang mengarah pada perilaku belajar-pengetahuan (Noble et al., 2002). 


\section{Orientasi Kewirausahaan}

Liu dan Fu (2011) mengatakan orientasi kewirausahaan membuat perusahaan memiliki kemampuan dalam aktivitas pengambilan keputusan guna meningkatkan nilai produk dan layanan untuk memenuhi kebutuhan pelanggan dalam peningkatan kinerja. Mohd Nazdrol, Breen, dan Josiassen (2011) serta Kaya dan Agca (2009) mengatakan orientasi kewirausahaan mencakup beberapa dimensi, antara lain pengambilan risiko (risk-taking), inovasi (innovation), dan proaktif (proactiveness). Pengambilan risiko mengarah pada sejauh mana manajer bersedia menggunakan sumber daya (Balodi, 2014). Lumpkin dan Dess (2005) membagi resiko menjadi tiga kategori, yaitu resiko keuangan, resiko bisnis, dan resiko pribadi. Perusahaan mengambil risiko dengan harapan mencapai pengembalian yang tinggi ( $\mathrm{Li}$ et al., 2010). Inovasi mengacu pada kebiasaan perusahaan yang terlibat dalam mendukung kreativitas, kegiatan eksperimental dan kreatif yang dapat menghasilkan produk, teknologi atau layanan baru (Lumpkin \& Dess, 1996). Seperti yang dikatakan Storey dan Hughes (2013), proaktif memberikan pandangan terhadap perusahaan dalam mengembangkan produk baik mengembangkan yang sudah ada maupun yang benar-benar baru, mampu menerima perubahan dari peluang, dan memprediksi kebutuhan pasar dimasa depan.

\section{Kinerja Organisasi}

Tseng dan Lee (2014) mendefinisikan kinerja organisasi sebagai kemampuan organisasi untuk mencapai tujuan yang sudah ditetapkan dengan memanfaatkan sumber daya secara efisien dan efektif. Kinerja organisasi terdiri atas kinerja organisasi, keuangan, dan sumber daya manusia. Antony dan Bhattacharyya (2010) mendefinisikan kinerja organisasi sebagai pengukuran seberapa baik organisasi dalam mengelola atau memberikan nilai kepada pelanggan serta pemangku kepentingan lainnya. Strategi perusahaan dibentuk guna meningkatkan kinerja organisasi dalam pertumbuhan penjualan dan sebagai pengukuran kinerja organisasi berdasarkan omset penjualan dan jumlah keuntungan (Voss \& Voss, 2000).

\section{METODE PENELITIAN}

Penelitian ini menggunakan data primer dengan melakukan penyebaran kuesioner kepada responden melalui Google Forms. Penelitian ini menggunakan dua variabel, yang pertama variabel independen dan yang kedua variabel dependen. Variabel independen yang digunakan yaitu Orientasi Pasar, Orientasi Teknologi dan Orientasi Kewirausahaan. Kemudian variabel dependen yaitu adalah Kinerja Organisasi. Metode yang digunakan adalah nonprobability sampling dengan jumlah kuesioner yang disebarkan sebanyak 100 responden dan menjadikan pelaku usaha kecil dan menengah di Jakarta sebagai subyek/obyek penelitian. Adapun metode analisis data yang digunakan dalam menguji hipotesis statistik dan pengujiannya menggunakan uji R-Square $\left(\mathrm{R}^{2}\right)$, uji F-Square $\left(\mathrm{F}^{2}\right)$, Q-Square $\left(\mathrm{Q}^{2}\right)$, uji GoF, pengujian menggunakan metode Bootstrapping dan pengujian F Simultan dengan bantuan program SPSS IBM 23.

\section{HASIL \& KESIMPULAN Uji R-Square $\left(\mathbf{R}^{2}\right)$}

\section{Tabel 1}

Hasil Uji R-Square $\left(\mathbf{R}^{2}\right)$

\begin{tabular}{|c|c|c|}
\hline Konstruk & R-Square Adjusted & Kesimpulan \\
\hline Kinerja Organisasi (Y) & 0,841 & Substansial/Kuat \\
\hline
\end{tabular}

R-Square yang diperoleh adalah sebesar sebesar 0,841 yang berarti substansial/kuat. Interpretasi dari hasil tersebut adalah bahwa sebesar $84 \%$ variabel kinerja organisasi dipengaruhi oleh variabel orientasi pasar, orientasi teknologi, dan orientasi kewirausahaan, kemudian sisanya sebesar 16\% variabel kinerja organisasi dipengaruhi oleh variabel lain di luar ketiga variabel independen yang digunakan dalam penelitian ini. 
Uji F-Square $\left(\mathbf{F}^{2}\right)$

Tabel 2

Hasil Uji F-Square $\left(\mathbf{F}^{2}\right)$

\begin{tabular}{|c|c|c|}
\hline Variabel & Effect Size $\left.\mathbf{~ ( F ~}^{\mathbf{2}}\right)$ & Keterangan \\
\hline Orientasi Pasar (X1) & 0,450 & Reliabel \\
\hline Orientasi Teknologi (X2) & 0,154 & Reliabel \\
\hline Orientasi Kewirausahaan (X3) & 0,087 & Reliabel \\
\hline Kinerja Organisasi (Y) & 0,000 & Reliabel \\
\hline
\end{tabular}

Hasil yang didapat adalah Orientasi Pasar memiliki dampak pada nilai R-square variabel Kinerja Organisasi kuat karena memiliki nilai $\mathrm{F}^{2} 0,450$ (kuat), Orientasi Teknologi memiliki dampak pada nilai R-square variabel Kinerja Organisasi lemah karena memiliki nilai $\mathrm{F}^{2} 0,154$ (lemah) dan Orientasi Kewirausahaan memiliki dampak pada nilai R-square variabel Kinerja Organisasi lemah karena memiliki nilai $\mathrm{F}^{2} 0,087$ (lemah).

Uji Q-Square $\left(\mathbf{Q}^{2}\right)$

Tabel 3

Hasil Uji Q-Square $\left(\mathbf{Q}^{2}\right)$

\begin{tabular}{|c|c|c|}
\hline Variabel & $\boldsymbol{Q}$-Square $\left(\mathbf{Q}^{2}\right)$ & Keterangan \\
\hline Kinerja Organisasi (Y) & 0,461 & Reliabel \\
\hline
\end{tabular}

Q-Square/predictive relevance yang dihasilkan adalah sebesar 0,461 > 0. disimpulkan bahwa konstruk yang digunakan dalam penelitian memiliki relevansi prefiktif dan tergolong kuat.

\section{Goodness of Fit Model (GoF)}

Tabel 4

Hasil Average Variance Extracted (AVE)

\begin{tabular}{|c|c|c|}
\hline Variabel & Nilai Average Variance Extracted & Nilai R $^{\mathbf{2}}$ \\
\hline Orientasi Pasar (X1) & 0,526 & - \\
\hline Orientasi Teknologi (X2) & 0,543 & - \\
\hline Orientasi Kewirausahaan (X3) & 0,537 & - \\
\hline Kinerja Organisasi (Y) & 0,596 & $\mathbf{0 , 8 4 1}$ \\
\hline Customer Orientation & 0,617 & - \\
\hline Competitor Orientation & 0,691 & - \\
\hline Inte-functional Coordination & 0,727 & - \\
\hline Innovativeness & 0,703 & - \\
\hline Risk-taking & 0,716 & - \\
\hline Proactiveness & 0,575 & - \\
\hline Financial Performance & 0,659 & - \\
\hline Non-Financial Performance & 0,641 & - \\
\hline AVE & $\mathbf{0 , 6 2 8}$ & - \\
\hline
\end{tabular}

Setelah nilai rata-rata AVE dan R-square yang diperlukan telah didapat, maka dapat dihitung besarnya GoF dengan menggunakan rumus berikut:

$$
\text { GoF }=\sqrt{ } \text { AVE } \times \text { R2 }=\sqrt{ } \mathbf{0 , 6 2 8} \times 0,841=0,727
$$

Hasil perhitungan diketahui bahwa nilai GoF pada model penelitian ini adalah sebesar 0,727 di mana dapat disimpulkan bahwa keseluruhan dalam kinerja model prediksi yang ditinjau pada tingkat kesesuaian antara inner model dengan outer model adalah memiliki tingkat kelayakan yang besar.

\section{Pengujian Hipotesis dengan Menggunakan Metode Bootstrapping}

\section{Tabel 5}

Hasil Pengujian Hipotesis Menggunakan Metode Bootstrapping

\begin{tabular}{|c|c|c|c|c|c|}
\hline Kode & Hipotesis & $\begin{array}{c}\text { Original } \\
\text { Sample }\end{array}$ & $\begin{array}{c}\mathbf{t}- \\
\text { statistics }\end{array}$ & $\begin{array}{c}\text { P- } \\
\text { values }\end{array}$ & Kesimpulan \\
\hline $\mathrm{H}_{1}$ & Orientasi pasar $\rightarrow$ kinerja organisasi & 0,466 & 5,710 & 0,000 & Diterima \\
\hline $\mathrm{H}_{2}$ & Orientasi teknologi $\rightarrow$ kinerja organisasi & 0,280 & 3,249 & 0,001 & Diterima \\
\hline $\mathrm{H}_{3}$ & Orientasi kewirausahaan $\rightarrow$ kinerja & 0,244 & 2,530 & 0,012 & Diterima \\
\hline
\end{tabular}


Berdasarkan hasil analisis data penelitian, maka kesimpulan dari penelitian ini adalah sebagai berikut:

Terdapat pengaruh yang secara signifikan antara Orientasi Pasar terhadap Kinerja Organisasi karena $\mathrm{P}$-Value $0,000<0,05$ yang berarti $\mathrm{H}_{1}$ tidak ditolak. Terdapat pengaruh yang secara signifikan antara Orientasi Teknologi terhadap Kinerja Organisasi karena P-Value 0,001 $<0,05$ yang berarti $\mathrm{H}_{2}$ tidak ditolak. Terdapat pengaruh yang secara signifikan antara Orientasi Kewirausahaan terhadap Kinerja Organisasi karena P-Value 0,012 <0,05 yang berarti $\mathrm{H}_{3}$ tidak ditolak.

\section{DAFTAR PUSTAKA}

Antony, J. P., \& Bhattacharyya, S. (2010). Measuring organizational performance and organizational excellence of SMEs - Part 2: An empirical study on SMEs in India. Measuring Business $\quad$ Excellence, $14(3), \quad 42-52$. https://doi.org/10.1108/13683041011074209

Badan Pusat Statistik. (2018). Berapa jumlah penduduk Indonesia? Katadata. https://databoks.katadata.co.id/datapublish/2018/04/23/berapa-jumlah-pendudukdunia\%0Ahttps://databoks.katadata.co.id/datapublish/2018/01/12/berapa-jumlahpenduduk-indonesia

Balodi, K. C. (2014). Strategic orientation and organizational forms: An integrative framework. European Business Review, 26(2), 188-203. https://doi.org/10.1108/EBR-08-2013-0106

Deshpandé, R., Grinstein, A., Kim, S. H., \& Ofek, E. (2013). Achievement motivation, strategic orientations and business performance in entrepreneurial firms: How different are Japanese and American founders? International Marketing Review, 30(3), 231-252. https://doi.org/10.1108/02651331311321981

Dess, G. G., \& Lumpkin, G. T. (2005). The role of entrepreneurial orientation in stimulating effective corporate entrepreneurship. Academy of Management Perspectives, 19(1), 147156. https://doi.org/10.5465/AME.2005.15841975

Gatignon, H., \& Xuereb, J. M. (1997). Strategic orientation of the firm and new product performance. Journal of Marketing Research, 34(1), 77-90. https://doi.org/10.1177/002224379703400107

Kara, A., Spillan, J. E., \& DeShields, O. W. (2005). The effect of a market orientation on business performance: A study of small-sized service retailers using MARKOR scale. Journal of Small Business Management, 43(2), 105-118. https://doi.org/10.1111/j.1540627x.2005.00128.x

KAYA, H., \& AĞCA, V. (2009). Entrepreneurial orientation and performance of Turkish manufacturing FDI firms: An empirical study. Iktisat Işletme ve Finans, 24(275), 115133. https://doi.org/10.3848/iif.2009.275.3157

Kohli, A. K., \& Jaworski, B. J. (1990). Market orientation: The construct, research propositions, and managerial implications. Journal of Marketing, 54(2), 1-18. https://doi.org/10.2307/1251866

Kongolo, M. (2010). Job creation versus job shedding and the role of SMEs in economic development. African Journal of Business Management, 4(11), 2288-2295.

Li, Y., Wei, Z., \& Liu, Y. (2010). Strategic orientations, knowledge acquisition, and firm performance: The perspective of the vendor in cross-border outsourcing. Journal of Management Studies, 47(8), 1457-1482. https://doi.org/10.1111/j.14676486.2010.00949.x

Liu, B., \& Fu, Z. (2011). Relationship between strategic orientation and organizational performance in born global: A critical review. International Journal of Business and Management, 6(3), 109-115. https://doi.org/10.5539/ijbm.v6n3p109 
Lumpkin, G. T., \& Dess, G. G. (1996). Clarifying the entrepreneurial orientation construct and linking it to performance. Academy of Management Review, 21(1), 135-172. https://doi.org/10.5465/AMR.1996.9602161568

Maming, M. (2019). HIPMI siap dongkrak jumlah pengusaha baru di Indonesia. Katadata. https://katadata.co.id/arsip/berita/5e9a5182aed13/hipmi-siap-dongkrak-jumlahpengusaha-baru-di-indonesia

Mohd Nazdrol, W., Breen, J., \& Josiassen, A. (2011). The relationship between strategic orientation and SME firm performance: Developing a conceptual framework. Proceedings of the 8th AGSE International Entrepreneurship Research Exchange, Swinburne University of Technology, Melbourne, 8, 713-724.

Narver, J. C., \& Slater, S. F. (1990). The effect of a market orientation on business profitability. Journal of Marketing, 54(4), 20-35. https://doi.org/10.2307/1251757

Noble, C. H., Sinha, R. K., \& Kumar, A. (2002). Market orientation and alternative strategic orientations: A longitudinal assessment of performance implications. Journal of Marketing, 66(4), 25-39. https://doi.org/10.1509/jmkg.66.4.25.18513

Setiawan, S. R. D. (2017). Sumber ekonomi baru Indonesia ada di tangan UMKM. Kompas.Com. https://ekonomi.kompas.com/read/2017/08/18/131057026/sumberekonomi-baru-indonesia-ada-di-tangan-umkm

Slater, S. F., \& Narver, J. C. (1994). Does Competitive Environment Moderate the Market Orientation-Performance Relationship? Journal of Marketing, 58(1), 46-55. https://doi.org/10.2307/1252250

Storey, C., \& Hughes, M. (2013). The relative impact of culture, strategic orientation and capability on new service development performance. European Journal of Marketing, 47(5), 833-856. https://doi.org/10.1108/03090561311306903

Tseng, S. M., \& Lee, P. S. (2014). The effect of knowledge management capability and dynamic capability on organizational performance. Journal of Enterprise Information Management, 27(2), 158-179. https://doi.org/10.1108/JEIM-05-2012-0025

Voss, G. B., \& Voss, Z. G. (2000). Strategic orientation and firm performance in an artistic environment. Journal of Marketing, 64(1), 67-83. https://doi.org/10.1509/jmkg.64.1.67.17993

Wales, W. J., Patel, P. C., \& Lumpkin, G. T. (2013). In pursuit of greatness: CEO narcissism, entrepreneurial orientation, and firm performance variance. Journal of Management Studies, 50(6), 1041-1069. https://doi.org/10.1111/joms.12034 